\title{
Dinler Tarihçisinin Anlamayı Hedefleyen Bir İmanlı Olarak Portresi: Joachim Wach
}

\author{
Betül AvcI*
}

Öz: Günümüz dinler tarihi disiplininin kurucularından sayılan Joachim Wach (1898-1955) aslında çok katmanlı bir yaklaşıma sahiptir. Bunlardan ilki, dinler tarihi disiplininin sınırlarını çizmeye ve metodunu belirlemeye çalışan bir dinler tarihçisi; ikincisi, din ve toplumun birbiriyle ilişkisini tipolojiler yoluyla sistemleştirmeye çalışan bir din sosyoloğu ve fenomenoloğu; üçüncüsü ise Tanrı'nın kendini İsa Mesih'te en üstün şekilde açımladığına inanan Hıristiyan bir imanlı ve Hıristiyanlık dışı dinlere nasıl yaklaşılması gerektiği üzerinde düşünen bir teolog. Elinizdeki bu yazıda Wach'ın "din sosyolojisi" adı altında nasıl bir din fenomenolojisi yaptığı, yarattığı tipolojiler ve mukayeseler vasıtasıyla nasıl bir teoloji ortaya koyduğunu ele alacağım. Üstelik bilimsel, otonom ve objektif metodolojiyi önceleyen bir dinler tarihçisi olma iddiasında olan Wach, ne tam bir dinler tarihçisi ne de tam bir teolog gibi davranabilmiştir.

Anahtar Kelimeler: Joachim Wach, dinler tarihi, Religionswissenschaft, din fenomenolojisi, din sosyolojisi, teoloji, tipoloji, mukayese.

Abstract: Joachim Wach (1898-1955), considered one of the founding fathers of the contemporary history of religions, has a multilayered personality: In order, he is a historian of religions who tries to demarcate the field's boundaries and determine its methods, a phenomenologist of religion as he attempts to systematize the relationship between religion and society via typologies, and a faithful Christian who believes in the superior revealing of God in the person of Jesus Christ as well as a theologian who reflects upon how to approach nonChristian traditions. Within the scope of this paper, I will argue that Wach's attempt to establish the history of religions as an autonomous, objective, and scientific discipline failed even in his own eyes as he is involved in the phenomenology of religion under the name of the "sociology of religion." In addition, he acts as a quasitheologian when he is involved in the phenomenology of religion and when he provides us with comparisons and typologies. Moreover, although Wach seems to be a historian of religions who prioritizes methodology, he does not fit into either the field of the history of religions or theology.

Keywords: Joachim Wach, history of religions, Religionswissenschaft, phenomenology of religion, sociology of religion, theology, typology, comparison.

* Yrd. Doç. Dr.,Yalova Üniversitesi, İslami Illimler Fakültesi, Dinler Tarihi Bölümü.

E-posta: betulavci27@gmail.com. Adres: Rüstempaşa Mh. Şehit Ömer Faydalı Caddesi No:146 Kat:3 Posta Kodu 77100 Merkez/Yalova.

DOI: dx.doi.org/10.12658/human.society.5.10.M0146

İnsan ve Toplum, 5 (10), 2016 


\section{Amaç}

Günümüz dinler tarihi disiplininin kurucularından sayılan Joachim Wach (1898-1955) ile ilgili bu yazıya başladığımda öncelikli amacım onun mukayeseli yaklaşımı içerisinde İslam dinine nasıl yer verdiğini incelemekti. Araştırdıkça, Wach'ın metodolojik bakımdan çok katmanlı olan kişiliğiyle karşılaştım. İlk olarak o dinler tarihi disiplininin sınırlarını çizmeye ve metodunu belirlemeye çalışan bir dinler tarihçisidir. İkincisi, Wach din ve toplumun birbiriyle ilişkisini tipolojiler yoluyla ve "din sosyolojisi" adı altında sistemleştirmeye çalışan bir din fenomenoloğudur. Wach'ın üçüncü yönü ise, Tanrı'nın kendini İsa Mesih'te en üstün şekilde açımladığına inanan Hıristiyan bir imanlı ve Hıristiyanlık dışı dinlere nasıl yaklaşıması gerektiği üzerinde düşünen bir teolog olmasıdır. Başlangıçta amaçladığım yazı farklı boyutlara evrildiği için Wach hakkında iki ayrı çalışma yapmaya karar verdim (bk. Avcı 2014). Elinizdeki bu yazıda öncelikle Wach'ın üç katmanlı entelektüel yaklaşımını ortaya koyup dinler tarihi disiplini içerisindeki yerinden bahsedeceğim. Ardından onun bir dinler tarihçisi, din fenomenoloğu, din sosyoloğu ve teolog olarak değerlendirmesini yapacağım. Sonuç olarak, günümüz dinler tarihi disiplininin kurucularından sayılan Wach çerçevesinde bu disiplinin din fenomenolojisi ile alakasını ve teolojiden ne derece uzaklaşabildiğini ortaya koymaya çalışacağım.

\section{Dinler Tarihinin Gelişimi ve Wach'ın Bu Disiplindeki Yeri}

On dokuzuncu yüzyılın sonları ile yirminci yüzyılın başlarında "Din Tarihi Okulu" olarak tercüme edebileceğimiz Religionsgeschichtliche Schule, Yahudilik, Helenistik, Babil, İran vs. dinleri ve kültürleri ile ilgili çalışmaları teolojiye dâhil etme çabasına girişmişti. Göttingen Üniversitesi'nde ortaya çıkan bu akımın önde gelen isimleri arasında Hermann Gunkel, Hugo Gressmann, Wilhelm Bousset, Johannes Weiss, William Wrede ve Ernst Troeltsch sayılabilir. Bu isimlerin üzerinde birleştikleri nokta, dönemin meşhur "isa'nın hayatı" çevresinde dönen liberal tartışmalara bir cevap vermekti. Çoğu Kitab-ı Mukaddes uzmanı ve teolog olan bu kişilerin yaklaşımı ise Hıristiyanlık tarihinin diğer dinlerin tarihî verileri ışığında/ çerçevesinde, onlarla mukayeseli olarak incelenmesiydi. Zira bu anlayışa göre Hıristiyanlık, ortaya çıkışı başta olmak üzere, diğer dinlerin içinde olduğu bir bağlamda şekillenmiştir. Bu düşünürlerin bugün anladığımız anlamda bir "dinler tarihi" okulu oluşturduğunu söylemek yerinde değildir. Çünkü onların başlıca üzerinde durdukları konu tikel bir din, yani Hıristiyanlık ve onun tarihiydi.' Bu yaklaşıma karşılık Karl Barth gibi teologlarla Joachim Wach gibi dinler tarihçileri her iki disiplinin de birbirinden ayrılması gerektiğini savundu. Wach'ın Religionsgeschichtliche okulunda eleştirdiği başlıca konu, yaklaşımlarının Hıristiyan teolojisi merkezli olması ve Hıristiyanlık dışı dinleri kendisi için malzeme olarak kullanmasıydı. Dinler tarihinin teolojiden ayrılması gerektiğini savunan, bu sebeple günümüz dinler tarihi disiplininin kurucularından sayılan Joachim Wach olmuştur.

1 Religionsgeschichtliche Schule pek çok yerde "dinler tarihi" olarak tercüme edilir. William Baird'in ifade ettiği gibi bu grubu "dinler tarihi" diye çoğul olarak adlandırmak yanlış tercümeden kaynaklanan bir durumdur. Zira Religionsgeschichtliche tabirindeki "s" çoğul değil, tekil aidiyet ekidir (Baird, 2003, s. 222). Religionsgeschichtliche Schule hakkında detaylı bilgi için bk. Chapman 2010. 
On dokuzuncu yüzyılın sonları ile yirminci yüzyılın ortalarında Avrupa ve ABD'de Yahudilik ve Hıristiyanlık dışındaki dinler büyük merak uyandırmaktaydı. Pek çok Amerikan üniversitesi "dinler tarihi" ya da "mukayeseli dinler" adıyla bölümler kurdu ya da seminerler düzenledi. Lakin bu bölümler genellikle Hıristiyan teolojisinin içinden çıkmaktaydı ve bir nevi Hıristiyan dinler tarihi olmaktan öteye gidemiyordu. Wach'ın Şikago Üniversitesi'ndeki öğrencilerinden ve kendisi de bir dinler tarihçisi olan Joseph M. Kitagawa'nın da ifade ettiği gibi, yirminci yüzyılın başlarında dinler tarihi şu dört açıdan büyük eleştiri almıştır: Birincisi, muhtelif dinlerin altında yatan aşkın birliğe işaret etmekle bir nevi din felsefesi olması; ikincisi, yeterince objektif olmaması; üçüncüsü, din mensubunun kendi tecrübesini ifade etmesine fırsat vermemesi; dördüncüsü, bu disiplinin misyolojinin bir dalı olması gerektiği savunusudur (Kitagawa, 1987, s. 6-7).

Dinler tarihi ya da Religionswissenschaft'ın münferit bir akademik disiplin hâline gelmeden önce ilgilendiği mevzular teoloji, felsefe, misyoloji, etnoloji, filoloji gibi disiplinlerin konusuydu. Wach, bu disiplini sadece teolojiden ayırmaya çalışmakla kalmamış, aynı zamanda onun sınırlarını çizmeye gayret etmiş ve "bilim" tabirini vurgulamak suretiyle Religionswissenschaft olarak adlandırmıştır. ${ }^{2}$ Fakat, Kitagawa'nın ifadesiyle, dinler tarihini felsefe ve bilimden ayırmaya çalışan Wach'a göre bu disiplin kendine has metodolojisi olan "dinî-bilimsel" bir alandır (Kitagawa, 1987, s. 17). Kitagawa, "dinî-bilimsel" kavramını ise şu şekilde açıklamaktadır: Her ne kadar Religionswissenschaft'ın başlangıç noktası ampirik, tarihî veriler olsa ve "betimleyici prensipler" kullansa da elde ettiği verilerle "dinî fenomenlerin anlamını" irdelemeye yönelmek zorundadır (Kitagawa, 1987, s. 19). Ayrıca Wach'a şerh düşmekte olan Kitagawa'ya göre dinler tarihi "otonom" olmakla birlikte "kendi kendine yeterli olmayan bir disiplindir" (Kitagawa, 1987, s. 17). Bu durumda, teoloji ve felsefe gibi normatif disiplinlerle sosyoloji, antropoloji ve diğerleri gibi betimleyici disiplinlerle işbirliği içinde olmalıdır (Kitagawa, 1987, s. 17-18).

1898 Saksonya doğumlu olan Joachim Wach Leipzig, Münih ve Berlin'de sürdürdüğü üniversite eğitiminde tarih, din felsefesi ve doğu dilleri üzerine yoğunlaştı. Leipzig Üniversitesi'ndeki doktorasını 1922 yılında bitirmesinin ardından aynı üniversitede ders vermeye başladı. Eric Sharpe'nin aktardığına göre, burada Friedrich Heiler tarafından mukayeseli din çalışmaları ile tanışan Wach'ın hocaları arasında Ernst Troeltsch, Adolf von Harnack, Nathan Söderblom, Rudolf Otto ve Max Weber yer almaktadır (Sharpe, 1975, s. 238). ${ }^{3}$ Wach ayrıca Wilhelm Dilthey ve Gerardus van der Leeuw'dan etkilenmiştir. 1924 yılında Habilitation tezini yazan Wach, daha sonra Heidelberg Üniversitesi'nden teoloji doktoru unvanını almıştır (Cox, 2006, s. 172). 1935 yılında Nazi baskısı yüzünden ABD’ye taşınmak zorunda kalan Wach, ${ }^{4}$ Brown Üniversitesi'nde on yıl ders vermiştir. 1945 yılında Şikago Üniversitesi'nde dinler tarihi kürsüsüne getirilen Wach, akademik kariyerine 1955 yılında

2 Joseph Kitagawa'nın tespitine göre Wach, 1944 yılına kadar Religionswissenschaft'ı "din tarihi (history of religion)" yani tekil olarak anlamışken, Şikago'ya gelişinden itibaren "dinler tarihi (history of religions)" şeklinde çoğul olarak ifade etmiş, "mukayeseli dinler çalışması (comparative study of religions)" tabirini de "dinler tarihi" ile aynı anlamda kullanmıştır (Kitagawa, 1988, s. xi, xxx).

Wach'ın hayatı hakkında detaylı bilgi için ayrıca bk. Kitagawa 1958: xiii-xlviii.

4 Wach hem anne hem baba tarafından filozof Moses Mendelssohn'un birkaç kuşak sonrası torunlarındandır. Wach ayrıca, müzisyen Felix Mendelssohn-Bartholdy ile akrabadır. Her ne kadar ailesi birkaç nesildir Hıristiyan olsa da Wach, Yahudi ataları sebebiyle Nazi Almanyası'ndan ayrılmak zorunda bırakılmıştır. 
ölene kadar burada devam etmiştir. Kendi deyişiyle Luteran olarak yetiştirilen Wach, ABD'ye geldikten sonra Amerikan Episkopal Kilisesi'ne katılmıştır (Wach, 1975, s. 143).

Günümüzde Şikago Okulu olarak üne sahip dinler tarihi kürsüsü Joachim Wach'ın hermenötik anlayışına çok şey borçludur. Zira Wach ABD'ye gelerek 1945 yılında Şikago Üniversitesi'ndeki dinler tarihi kürsüsünün başına geçtiğinde bu disiplin, teolojinin içinde kaybolmuş durumdaydı. James Cox'un deyişiyle, Wach bu durumu "tersine çevirip dinler biliminde 'hermenötik yaklaşım' olarak bilinen anlayışın uluslararası öncüsü" olmuştur (Cox, 2006, s. 171). Wach, "dinler tarihi" ve "mukayeseli din çalışmaları" olarak da adlandırılan Religionswissenschaft'ın günümüzde münferit bir disiplin hâline gelmesi için yoğun çaba sarf etmiştir. Dinler tarihini normatif teolojiden ayırıp betimleyici olan münferit bir disiplin hâline getirmek Wach'ın ABD'ye gelmeden önce gerçekleştirmeye koyulduğu bir plandı.

Rainer Flasche Wach'ın entelektüel serüvenini bilimsel metodu ve amacı itibarıla "erken" ve "sonraki" diye iki döneme ayırır. Flasche'ye göre Wach, Almanya'daki döneminde Religionswissenschaft'ın tarihî ve felsefi temelleriyle ilgilenirken Amerika'da yaşadığı dönemde bir bilim adamından ziyade dinler teolojisi ile ilgilenen bir vaiz olmuştur (Flasche, 1978, s. 73). ${ }^{5}$ Bu ayrımda Wach, erken döneminde Religionswissenschaft'ı teoloji ve felsefenin boyunduruğundan kurtarmaya çalışırken dinin özünün ve hakikatin ne olduğu sorularını dışlar. Kitagawa ise Wach'ın düşünce kariyerindeki üç safhadan şöyle bahseder: Birincisinde, kendi hermenötik çalışmasının içerisinde dinî tecrübeyi anlama çabasında olan Wach, dinler tarihinin metodolojisini ve teorik çerçevesini çizmektedir; ikinci döneminde din sosyolojisi üzerinde duran Wach, üçüncü döneminde dinler tarihinin sosyal bilimler, felsefe ve muhtelif teolojilerle ilişkisini yeniden değerlendirmektedir (Kitagawa, 1988, s. ix-xxxiv). Aşağıdaki satırlarda Kitagawa'nın Wach ile ilgili ortaya koyduğu bu dönemsel tasnifi takip etmek suretiyle Wach'ın farklı yönlerini derinlemesine incelemeye çalışacağım.

\section{Dinler Tarihçisi Olarak Wach}

Wach'ın bu döneminde ortaya koyduğu başlıca çalışmaları Habilitation tezi olarak kaleme aldığı Religionswissenschaft: Prolegomena zu ihrer wissenschaftstheoretischen Grundlegung (1924) ile sonrasında yazdığı Das Verstehen'dir (1926-1933). Sözü geçen birinci çalışmasında Wach, Religionswissenschaft ya da dinler tarihinin teoloji ve felsefe gibi normatif disiplinlerden ayrılarak münferit bir alan olarak algılanması gerektiğini savunmuş ve bu disiplinin amacını, metodunu ve bölümlerini anlatmıştır. ${ }^{6}$ Ona göre bu bilim normatif, iman merkezli

5 Rainer Flasche'nin aslen Marburg'da Habilitationsschrift olarak hazırladığı çalışma başlıca üç kısımdan oluşmaktadır. Birinci bölümde Flasche, Joachim Wachıın entelektüel geri zemininden bahsederken ikinci bölümde Wachıı Religionswissenschaft anlayışını derinlemesine inceler. Çalışmanın üçüncü kısmı ise Wach'ın teorilerinin geçerliliği üzerinedir. Ayrıca Charles M. Wood'un Theory and Understanding: A Critique of the Hermeneutics of Joachim Wach (1975) adlı kitabı Wach üzerine önemli monografik bir çalışmadır.

6 Bu meyanda bir yönerge ya da bildirge olarak adlandırabileceğimiz bu çalışma günümüzde Türkiye'deki dinler tarihi anlayışılla neredeyse tamamen paraleldir. Kanaatimce, bu da Wach'ın Türkiye akademisinde ne kadar etkili olduğuna bir delildir. Introduction to the History of Religions (1988) adıyla Ingilizce'ye aktarılmış ve hitap alanı genişlemiş olan bu eser, Fuat Aydın tarafından Dinler Tarihi: Bilimsel Bir Disiplin Olarak Kuruluşuna Teorik Bir Giriş (2004) adıyla Türkçe'ye kazandırılmış ve Türkiye akademisinde hala dinler tarihi disiplininin başlıca kaynaklarından biri olarak kullanılmaktadır. Wach, Türkçe konuşan akademide genellikle ilk dönemindeki hâliyle tanınagelmiştir. Halbuki Wach’ın son dönemlerinde ortaya koyduğu eserler daha renkli ve ince ayrımlıdır. Wach üzerine Türkçe yazılanlara örnek için ayrıca bk. Alıcı 2005. 
ve ideolojik yaklaşımları, yani değer yargılarını askıya almalıdır (epoché). Wach'a göre, dinler tarihinin amacı halihazırda tecrübe edilen (ampirik) dinleri tarif etmekti. Ona göre dinler tarihi normatif değil, betimleyici (descriptive) ve yorumlayıc (interpretative) bir disiplindir ve dinî fenomenleri tarihsel ve sistematik açıdan incelemek suretiyle görevini ifa eder. Wach dinler tarihi araştırmalarının "tarihsel" ve "sistematik" olmak üzere iki, dinî tecrübenin ifade edilişinin ise "teorik," "pratik" ve "sosyolojik" olmak üzere üç boyutunun olduğunu savunmuştur. Wach'a göre, dinler tarihi araştırmalarındaki "tarihsel" boyut spesifik dinlerin doğuşu ve tarih içerisinde geçirdiği süreçle ilgilenirken, "sistematik" boyut dinî fenomenlerin sistematik yapısı ile ilgilenmektedir. Sistematik boyut, başka bir ifadeyle, dinî fenomenlerin kurallar dâhilinde genellemeler yapılıp eldeki verilerin yapısal bir örgü (structure) hâline getirilmesiyle uğraşır. Wach'a göre asıl yapılması gereken dinî fenomenlerin sadece tarih içerisinde geçirdiği süreçle ilgilenmek suretiyle tarihsel bilgi veri tabanı oluşturmak değil, elde edilen bu bilgileri yapısal bir örgü hâline getiren prensibi ve bunun altında yatan anla$m ı$ keşfetmektir. Wach, ilk döneminden başlayarak kendini motive eden soruları 1952'de Hindistan'da verdiği bir dizi derste şöyle ifade eder:

Sürekli ilgimi çeken ve hakkında yazdığım sorunlardan biri anlama, ya da daha teknik bir ifadeyle, yorumlama sorunudur. Diğer insanları, kendimizden farklı olan kişileri, diğer medeniyetleri, diğer dinleri anlamak ne demektir? Anlama olarak adlandırdığımız bu sürecin doğası nedir? Anlamanın dereceleri var mıdır? Yorumlayanın önceden var saydığı şeyler nelerdir? Anlamanın çeşitleri var mıdır? Peki ya sınırları? (Wach, 1975, s. 143).

Wach esasen dinler tarihinin kökeninin felsefe olduğunun farkındaydl; zira dinler tarihi felsefenin spekülatif çıkarımları için ampirik veri sağlamaktaydı (Wach, 1988a, s. 8-9). O, her ne kadar Religionswissenschaft'ın hem tarihî hem de sistematik veri sağladığı sürece görevini ifa etmiş olduğunu ve bunun ötesine geçmediğini iddia etse de, dinler tarihçisinin düşüncelerinin ardında felsefi varsayımların bulunduğunun farkındadır (Wach, 1988a, s. 83). Diğer bir nokta ise, Wach dinlerin Hegel ve benzerlerindeki gibi tekâmülcü tasnifini reddetse de kendisi de "klasikler" dediği tipolojik tasnifini yapmaktan geri durmamıştır (Wach, 1988a, s. 59). Wach sistemleştirmekten kastın özetlemek, gruplamak ya da sınıflandırmak olmadığını iddia etse de kendi tipolojileri bunlardan uzak kalamamıştır (Wach, 1988a, s. 121-122).

Teolojiden bağımsızlığını ilan etmeye çalışan Religionswissenschaft'ın kullandığı başlıca metotlardan birisi de fenomenoloji olmuştur. Wach'a göre din biliminin fenomenolojik yaklaşımını Husserl ya da Scheler'in fenomenolojisinden ayırt etmek gerekir. Zira Religionswissenschaft'ın "fenomenoloji"den anladığı, herhangi bir dinî fenomenin "sistematik" olarak ortaya konması, yani sınıflandırılmasıdır (Wach, 1944, s. 1, dipnot 3).7 Işste Wach sosyolojisini "tipoloji" olarak adlandırdığı bu sınıflandırmalar üzerine bina eder. Sonuç olarak, James Cox'un da ifadesiyle, "Wach'ın sosyolojisi tamamen fenomenolojiktir" (Cox, 2006, s. 173).

7 Wach defalarca dinler tarihi disiplininin iki boyutundan bahseder: tarihî ve sistematik. Douglas Allen modern dönemde "din fenomenolojisi" teriminin başlıca dört kullanımından bahseder: Birincisi, genel anlamda dinî fenomenlerin araştırılması; ikincisi, felsefi fenomenolojiden etkilenen din fenomenolojisi; üçüncüsü, Chantepie de la Saussaye, Geo Widengren ve Åke Hultkrantz gibi din fenomenolojisini farklı dinî fenomen çeşitlerinin sınıflandırılması ve mukayesesi olarak anlayanlar; dördüncüsü ise W. Brede Kristensen, Gerardus van der Leeuw, Joachim Wach, C. Jouco Bleeker, Mircea Eliade ve Jacques Waardenburg gibi din fenomenolojisini Religionswissenschaft'ın bir dalı ya da metodu olarak görenlerdir (Allen, 2005, s. 185). 


\section{Din Sosyoloğu ve Din Fenomenoloğu Olarak Wach}

Wach'ın entelektüel hayatındaki ikinci safha ise dinler tarihinin sosyal boyutunu tipolojiler vasıtasıyla ortaya koyduğu, ya da kendi tanımıyla, dinî fenomenlerin "sistematik" boyutuyla ilgilendiği dönemdir. Bu döneminde Wach'ın Gerardus van der Leeuw'nun izinden giden yapı kurucu bir fenomenolog ${ }^{8}$ ve Weber'in izinden giden bir din sosyoloğu olduğunu söyleyebiliriz. ${ }^{9}$ Aslında Wach, Weber'den ilham alsa da onun gibi diğer dinler hakkında topladığı bilgilerle bir diskur oluşturamayacak kadar çekingendir. Aslında Wach'ın din sosyolojisi mukayeseler ve tipolojiler üzerine inşa edilmiş bir fenomenoloji olmaktan öteye gidememiştir.

Wach'ın bu döneme ait eserleri arasında Einführung in die Religionssoziologie (1931), Typen religiöser Anthropologie (1932) ve Sociology of Religion (1944) gelmektedir. Wach bu dönemde ABD'ye gelmiş ve Brown Üniversitesi'nde ders vermiştir (1935-45). Kendi ifadesiyle, Amerika'da din sosyolojisi alanında yazılmış bir ders kitabı olmadığını görmüş, "din ve toplum arasındaki ilişkiyi incelemek" ve "dinî toplulukların bir tipolojisini ortaya koymak" maksadıyla Sociology of Religion'ı yazmıştır (Wach, 1975, s. 143). ${ }^{10}$

Wach Sociology of Religion'ın girişinde "normatif" bir disiplin olarak adlandırdığı teolojiyi genel din biliminden yani Religionswissenschaft'tan ayııır ve Religionswissenschaft'ın başlıca dört dalından bahseder: din fenomenolojisi, tarihi, psikolojisi ve sosyolojisi (Wach, 1944, s. 1). Wach burada dinî tecrübenin ifade ediliş şekillerini başlıca üç kısma ayırır: teorik, pratik ve sosyolojik. Teorik boyuttan kastı doktrin, dogma, mit, teoloji ve ahlak; pratik boyuttan kastı kültler, ayinler ve ibadetler; sosyolojik boyuttan kastı ise dinî gruplar, kurumlar ve benzerleridir. Kitap, pek çok yönden Weber'inkini andıran dinî otorite sınıflandırması ile son bulur. Wach dinî otorite çeşitleri arasında reformcu, peygamber, aziz, kâhin ve diğerlerini anmaktadır. Tüm bu sınıflandırmaları yaparken de Zerdüştîlik, Şintoizm, İslam, Budizm, Hıristiyanlık, Konfüçyüsçülük ve pek çok farklı gelenekten örnekler vererek tipolojilerinin sağlamasını yapmaya çalışır.

Wach'a göre sistematik din çalışmasının amacı, kendi deyişiyle, "dinî tecrübenin ifade edilişinin farklı şekilleri arasındaki ilişkiye nüfuz etmek, nihayetinde de dinî tecrübenin muhtelif veçhelerini daha iyi kavrayabilmektir" (Wach, 1944, s. 5). Wach'a göre kendini yüzeysel görünüşlerle sınırlamak istemeyen, amacını sadece olay ve veri toplamak olarak görmeyen herhangi bir dinler tarihî incelemesi, tikel dinî fenomenleri bir araya getirip onları tanzim edecek bir prensip arayışında olmalıdır. Böyle bir prensip vasıtasıyla tarihî sürecin detayları anlaşılabilir. Bu sebeple sistematik çalışma, tikelleri anlamada anahtar rolü oynayacak "merkez" ile ilgile-

8 Din fenomenolojisinin en önemli isimlerinden olan Gerardus van der Leeuw aslında bir Hıristiyan teoloğudur ve yer yer Hıristiyanlığın dinin en üst formu olduğunu iddia etmekten çekinmez. Van der Leeuw'nun fenomenolojisi teolojiktir ve içerisinde pek çok değer yargısı barındırmaktadır. Zira ele aldığı dini fenomenleri, tarihî ve kültürel bağlamlarından soyutlamakta, öznel ve spekülatif yorumlara kaçmaktadır. Wach, van der Leeuw'yu teolog olmasının yanı sıra, dinler tarihi alanında da önemli bir isim olarak anmaktadır (Wach, 1975, s. 70).

9 Wach, Max Weber'in "sistematik din sosyolojisini tasarlayan ilk kişi" olduğunu iddia etmektedir (Wach, 1944, s. 3). Kitagawa'ya göre Wach, din sosyolojisinde diğerlerinin yanı sıra Weber ve Dilthey'ın etkisindedir (Kitagawa, 1988, s. xiii).

10 Cox'un belirttiğine göre bu kitap Wach'ın Brown Üniversitesi'ndeyken verdiği lisans dersleri üzerine inşa edilmiştir (Cox, 2006, s. 173). 
nir (Wach, 1988a, s. 38). Sonuç olarak, Wach'a göre, başlıca konusu Hıristiyanlık dışı dinler ve amacı bunları anlamak olan dinler tarihçisi kuru tarihselci yaklaşımı aşabilmek için dinleri sistematik bir şekilde ele alacak; bunu yaparken de iki metot kullanacaktır: tipoloji ve mukayese.

Wach, özellikle The Comparative Study of Religion ve Sociology of Religion adlı eserlerinde "tipler (types)" olarak adlandırdığı dinî fenomenlere ait pek çok kategori sunar. Wach, her ne kadar dinler tarihinin kategorilere karşı olduğunu iddia etse de içinden çıktığı Avrupa ve Hıristiyan merkezli din kategorilerinden uzak duramazdı. Zira kendi dönemi —özellikle on dokuzuncu yüzyılda başlayan- Avrupalı fenomenologların kategorilerinin revaçta olduğu bir zamandı. Böylece Wach, hâlihazırda biliyor olduğu dinî fenomenleri, aralarındaki benzerliğe dayalı olarak sınıflandırdı ve kendi tipolojilerini yarattı. Gregory Alles'in de ifade ettiği gibi Wach’ın tipolojileri siyasi bir düzenleme değil, gayet zengin ve karmaşık bir dinî kavramlar bütününü "düzene sokma yöntemiydi" (Alles, 2010, s. 58).

Wach'ın tipolojileri özellikle din sosyolojisi ile ilgilendiği dönemde —ya da bağlamda— göze çarpar. Ona göre tipoloji, yapıları analiz eder ve ampirik detaylardan tipik olanı çekip çıkarır, dinî fenomenler arasındaki benzerlikler ve şablonlarla ilgilenir. Wach tipolojiden ne anladığını şu şekilde açıklar:

Ampirik-fenomenolojik çalışma ile normatif olan arasındaki köprü bir başka yaklaşımla ikmal ediliyor: tipoloji. Tarih, psikoloji ve din sosyolojisinin sunduğu sonsuz çeşitlilikteki verinin tanzim edilmesi gerekir. Tipoloji çalışmaları tam da bunu yapmak üzere tasarlanmıştır. Tarihçinin hayatları üzerine ışık tuttuğu, psikoloğun entelektüel ve duygusal dünyalarını araştırdığı, sosyoloğun toplumsal rollerini irdelediği dinî lider tipleri ortaya çıkar. Bunun yanı sıra dinî grup ve kurumlar belli başlı tipler olarak karşımıza çıkar. Wilhelm Dilthey, William James, Max Weber ve Howard Becker bu metodu ustalıkla kullanmışlardır (Wach, 1988b, s. 133).

Wach "klasik" kavramını da "tipik" ile aynı anlamda kullanmıştır. Ona göre klasik olarak tavsif edeceğimiz fenomende "tipik" bir özellik vardır. Öyle ki, bu klasik olan fenomen "dinî hayata ve tecrübeye dair herhangi tikel bir örneğinkinden daha çok şey ifade eder." Wach, akabinde Meister Eckhart'ı, Gazzali'yi ve Şankara'yı "klasik mistikler"e örnek olarak gösterir (Wach, 1951, s. 51). Zira ona göre bu şahısların öğretilerinde "tipik mistik" bir boyut mevcuttur (Wach, 1951, s. 52). Mamafih, sistematik bir yapısı olan tipolojinin kendi kendine yeterli olmadığının farkında olan Wach, normatif yargılar ortaya koyamayacak olan dinler tarihçisinin görevinin tipolojileri ortaya sermekle bittiğinin de farkındadır (Wach, 1951, s. 228-229). Ona göre tipolojinin hem felsefe hem de teoloji ile alakası burada ortaya çıkar. Tipolojik çalışma hakikati ortaya koyma iddiasında olmadığı için bundan sonrası felsefe, özellikle de teolojinin işidir (Wach, 1988b, s. 133).

\section{Teolog Olarak Wach}

Wach, tipolojilerini ortaya koymak, klasik olana ulaşmak için mukayeseyi sıklıkla kullanmıştır. Fakat Wach için mukayese bununla sınırlı kalmaz. Zira onu sıklıkla kendi Hıristiyan tecrübesini diğer dinî geleneklerle kıyaslarken buluruz. Bunu bir öğretmen olarak pedagojik sebeplerle yapmasının yanı sıra, bu yaklaşımı dinlerin altında yatan ortak hakikat ve manevi derinlik arayışından kaynaklanır. İşte bu noktada Wach, manevi derinlik arayışındaki bir imanlı olarak karşımıza çıkar. 
Wach'a göre "diğer" dinleri öğrenmek ve öğretmek kişinin kendi dinî tecrübesini daha derinlemesine anlamasını sağlar. Wach'a göre, diğer dinlerdeki inanç esaslarını kabul edemesek de "dinî tecrübenin bazı kısımları kendi dinî tecrübemizi derinleştirmemizde bize yardımcı olabilir." Zira "insan doğası benzer hislere sahiptir" ve mukayeseli bir yaklaşım "duygularımızı hem nitelik hem de nicelik yönünden derinleştirecektir." Ayrıca Wach'a göre mukayese, "dinin doğasını keşfedebilmek için" önemli bir yoldur (Wach, Lecture Notes, s. 68). Wach bu mevzu üzerinde The Comparative Study of Religions'da daha da fazla durur ve şu tespiti yapar: "yeni asrın mümkün kıldığı dinlerin mukayeseli çalışııması dinî tecrübenin ne anlama gelebileceğini, bu tecrübenin hangi şekillerde ifade edilebileceğini ve insan için ne yapabileceğini daha geniş ölçekte görmemizi sağlar." Wach mukayeseli din çalışmalarının kayıtsızlığa sebebiyet vereceği eleştirisine katılmaz; aksine, ona göre bu tarz çalışmalar kişiye dinî tecrübenin anlamına dair daha "zengin bir görüş" ve "perspektif" kazandırır (Wach, 1958, s. 9).

Wach'ın fikirlerinin üçüncü evresi, Şikago Üniversitesi'nde bulunduğu 1945-55 yılları arasındaki zaman dilimidir. Bu dönemde Wach, dinler tarihinin teoloji ile ilgisini irdelemenin yanı sıra Hıristiyanlığın diğer dinlerle ilişkisini inceleyen bir Hıristiyan teoloğudur. Wach'ı bu döneminde saf rölativizme karşı araştırmacının öznelliği ve değer yargılarına yer vermekte ve elde ettiği bilgilerle ne yapılması gerektiği sorusuna cevap aramakta iken buluruz. Bu süreçte Wach, Types of Religious Experience: Christian and non-Christian (1951) ile ölümünden sonra yayımlanan The Comparative Study of Religions (1958) adlı eserleri kaleme almıştır. Bunların yanı sıra, yine ölümünden sonra Understanding and Believing (1968) ${ }^{11}$ adlı kitapta toplanan makale ve vaazlarını bu dönem yapıtları arasına koymak uygun olur.

Aslında teolog Wach sadece son zamanlarında değil Almanya'dan ABD'ye yeni göç ettiği yıllarda da karşımıza çıkar. Örneğin, 1935 yılında yayımlanan "Sinn und aufgabe der Religionswissenschaft" adlı yazısında Wach, teoloji ile dinler tarihinin alakasını ele alır. Wach'a göre teoloji kendi inancını ve iman esaslarını anlamak ve teyit etmek amacındadır. Asıl amaç ve alanı bu olmamakla birlikte teoloji, "yabancı dinlere" ilgi duyabilir. İşte tam da bu noktada, "yabancı dinleri" araştırmak gayesiyle meydana getirilmiş dinler tarihi devreye girer (Wach, 1975, s. 125-126). ${ }^{12}$ Başka bir deyişle, dinler tarihinin başlıca amacı "diğer dinleri anlamak"tır (Wach, 1975, s. 130). Peki, kendininkinin dışındaki dinlerin araştııılması sadece kuru entelektüel bir merak mıdır? Wach bu soruya olumsuz cevap verir: “...eğer Religionswissenschaft sadece estetik olarak ilginç ya da yalnızca akademik bir mesele olsaydı, hakikaten bugün var olmaya hakkı olmazdı" (Wach, 1975, s. 126). Wach'a göre, dinler tarihi insandaki "din duyusunu (sensus numinis), dinî his ve anlayışı, genişletir ve derinleştirir; kişiyi kendi inancını daha derinlemesine kavraması için hazırlar" (Wach, 1975, s. 127). Wach, aynı bağlamda mukayeseli din çalışmalarından da bahseder. Wach'a göre, dinler arasındaki benzerliklerin ve ilişkilerin ortaya konması kişinin dinî inancı üzerine olumsuz etki yapmaz. Bilakis, böyle bir çalışma "tanrısız, yabancılaşmış güçlere karşı savaşta yardım ve destek olabileceği" gibi kişiyi "kendi dinî inancını araştırmaya ve muhafaza etmeye yönlendirir" (Wach, 1975, s. 128) ve bu inancı "derinleştirir" (Wach, 1975, s. 138).

12 "Sinn und aufgabe der Religionswissenschaft"adıyla ZeitschriftfürMissionskundeund Religionswissenschaft'ta 1935 yılında yayımlanan bu yazı, "The Meaning and Task of the History of Religions (Religionswissenschaft)" adıyla Wach'ın yazılarının bir derlemesi olan Understanding and Beliving (1975)'de yayımlanmıştır. 
Bu esnada Wach sadece Hıristiyanlık dışı dinlerin ne ifade ettiği ile ilgilenen bir teolog ya da vahyin en kâmil anlamda İsa Mesih'de açımlanacağına inanan bir imanlı değil, aynı zamanda İsa Mesih'in mesajının nasıl yayılacağı üzerine kafa yoran, inkültürasyonu önceleyen bir misyonerdir. Örneğin, "Redeemer of Man"de modern insanın İsa Mesih'e nasıl yabancılaştığı üzerinde durur. Wach'a göre bu durumun bir etkeni Hıristiyanlık dışındaki dinler hakkındaki bilginin artmasıyla doğu dinlerine duyulan ilgidir. Ona göre Muhammed, Buda, Konfüçyüs, LaoTzu'ya duyulan ilginin başlıca iki sebebi vardır: Birincisi, Hıristiyan geleneğinden uzaklaşma ile "yeni"ye olan iştiyak; ikincisi ise, diğer dinî geleneklerdeki yüksek maneviyattır (Wach, 1975, s. 99-100). Akabinde, Wach bu durum için iki ayaklı bir çözüm önerir. Birincisi, toplumdaki bu yabancılaşmanın sebeplerini derinlemesine incelemek; ikincisi, doğu dinlerindeki hikmet ve manevi zenginliği araştırıp öğrenmektir. Wach'a göre, eskiden "entelektüel bir meraka" matuf yapılan ve "bilim insanının bir lüksü" (Wach, 1975, s. 100) olan bu tarz araştırmalar artık —bizzat kendisini de içine kattığı — "teologlar ve din adamlarının vazifesinin varoluşsal bir unsurudur" (Wach, 1975, s. 101). Zira çağdaş teoloğun yapması gereken "İsa Mesih'in mesajını Hıristiyan ve eski Hıristiyan olan ve de Hıristiyan olmayan dünyaya tercüme etmek," bunun için ihtiyaç duyulan ise "tüm mevcut bilgi, kaynaklar, vasıtalar ve bir araya getirilebilecek yöntemlerdir" (Wach, 1975, s. 101). Wach'ın aynı misyon kaygısını Şikago Üniversitesi'ndeki Bond Şapel'de yaptığı "Belief and Witness" başlıklı konuşmasında da görebiliriz. Wach burada bir Hıristiyan'ın sadece "kendi işine bakıp" Hıristiyanlığın mesajını, yani imanı, ümidi ve sevgiyi, tüm insanlıkla paylaşmadan edemeyeceğini savunmakta, akabinde ise çağdaş dünyada İsa Mesih'in mesajının nasıl yayılabileceğini soruşturmaktadır (Wach, 1975, s. 121).

Wach bir Hıristiyan olarak dinler teolojisi ile özellikle "General Revelation and the Religions of the World" (1954) adlı yazısında ilgilenmiştir. ${ }^{13}$ Burada dinler tarihi ile teoloji arasındaki boşluğun doldurulmasıyla ilgili şunları kaydeder:

Dinler tarihçisi on dokuzuncu yüzyılın sonundan beri kendisini sadece tasvir ve kataloglama yapmaya hapsetmiş saf ampirik yaklaşımı aşması gerektiğini kabul etmeye, teologların pek çoğu da dinler tarihçilerinin kendilerine sunduğu yeni malzemeyi göz önünde bulundurmak ve kendi işlerini görürken bunlardan faydalanmaları gerektiğini kabul etmeye hazırdır. Yorumun gerçekleştirileceği bakış açısı ise Hıristiyan teolog için Hıristiyanlığın prensipleri, Yahudi teolog için Tevrat, Müslüman (Mohammedan) teolog için ise İslam inancı olacaktır. Geçtiğimiz asrın eleştirel yöntem ve tarihsel araştırma konusundaki başarıları elbette korunmalıdır, lakin bu onların başı başına amaç olarak görülmeleri anlamına gelmemelidir. Son elli yıl normatif ilginin yeniden canlanmasına, kendi inancımızı telaffuz etmeye duyulan iştiyaka şahit oldu. Bu telaffuz on dokuzuncu yüzyılda vuku bulan ufuk genişlemesini dikkate almaktadır ve her şeyden öte Hıristiyan geleneğine derinlemesine kök salmıştır (Wach, 1975, s. 72-73).

Wach'ın Hıristiyanlığı ne derece öncelediği özellikle diğer dinler ile Hıristiyanlığı karşılaştırdığında ortaya çıkar. Wach'a göre tüm dinler aynı statüde değildir, zira Hıristiyanlık en üst konumdadır. Örneğin, Hıristiyanlığın tanıısı, Wach'ın deyişiyle "ne Vedenta'daki kayıtsız ve mesut figür, ne gnostiğin yabancılaşmış tanrısı, ne Talmud'da ya da Kur'an'daki tamamen katı yargıçtır..." (Wach, 1975, s. 90). Hatta aşağıdaki satırlarda olduğu gibi Wach, İsa Mesih'e tam anlamıyla iman etmesinin diğer dinlerle karşılaştıktan sonra gerçekleştiğini itiraf eder:

13 Kitagawa'nın aktardığına göre, bu yazı aslen Wach'ın Evanston, Illinois'de National Association of Biblical Instructors adlı kuruluşun 1953 yılı Aralık ayındaki toplantısında yapmış olduğu konuşmanın ertesi yıl The Journal of Bible and Religion adlı dergide basılmış halidir (Kitagawa, 1975, s. xv). 
Eğer bugün Hıristiyan isem, bunun sebebi öyle doğup büyümüş olmam değildir. Öyle bir zaman geldi ki, Hıristiyanlığa çok eleştirel baktığım, doğru yol ve aydınlanmayı başka yerde aradığım oldu. Lakin çevreyi araştırdığımda ve çeşitli dinî tecrübeleri derinlemesine incelediğimde ikna oldum ki, İsa Mesih benim Efendim ve Kurtarıcım ve de âlemin ışığıydı. Bu kavrayış beni ilim ve araştırma açısından bozmak şöyle dursun, bana tarifsiz yardım sağladı ve şevk verdi. Bu durum Hıristiyanlığı tamamen doğru, Hıristiyanlık dışı dinleri tamamen yanlış bulacağım anlamına gelmez. Hıristiyanlığın olması gereken ideal durumu ile şu anki reel hâli —istisnasız tüm hâlleri- arasındaki zıtlık Hıristiyanlığı bilinçli bir şekilde kendi normum olarak benimsediğim andan itibaren zihnimde capcanlıdır. Tersine, tamamen kanaat getirdim ki, Hıristiyanlık dışı dinlerde İsa Mesih'e olan benzerlik o kadar çok, İsa Mesih adına o kadar çok düşünce ve işleyiş var ki siyah-beyaz resimler benim için hiçbir anlam ifade etmedi (Wach, 1975, s. 144).

Görülüyor ki, Wach'a göre Hıristiyanlık dışı dinlerde de hakiki anlamda kutsalın tecrübesi vardır. Fakat diğer dinlerdeki ilahi boyutu kabul etmek İsa Mesih'de açımlanan Hıristiyan vahyinin "özel"14 vahye mazhar olan dinlerden sadece biri olduğunu kabul etmek değildir. Bilakis, "daha kısıtlı vahiyler (lesser revelations)" (Wach, 1975, s. 76) Hıristiyan vahyinin eşsizliğini ispatlamaktadır (Wach, 1975, s. 75-76). Yani Wach, dinler teolojisi açısından bakılacak olunursa ne dışlayıcı, ne de saf rölativisttir. Hıristiyanlık dışındaki dinlerde de ilahi hakikat olacağı gerçeğini kabul etmek suretiyle "kapsayıcı" bir söylem ortaya koymaktadır. ${ }^{15}$

\section{Sonuç: Mukayeseler, Tipolojiler ve Wach'ın Teolojisi}

Son iki yüzyıldaki dinler tarihi çalışmaları Yahudi-Hıristiyan geleneği dışındaki dinler ve inanç sistemlerine duyulan ilgi ve dinî fenomenler hakkında mümkün olan en fazla bilginin toplanması şeklinde başlamıştır. Bu çalışmalarda en fazla dikkat çeken nokta ise mitolojilere duyulan ilgi ve bunlar arasındaki paralelliklerin ortaya konması olmuştur. Bu disiplinin "mukayeseli dinler (Vergleichende Religionswissenschaft)" şeklinde adlandırılmasının en büyük sebeplerinden biri de budur. Max Müller ve James Frazer'ın çalışmaları buna örnek birer mukayese ya da benzerlikler antolojisi mesabesindedir. Lakin Wach'ınkilerin de içinde bulunduğu dinler ve dinî fenomenlere ait mukayeseler, mukayeseye dayanan tipolojiler ve kavramlar pek çok yönden sorunludur. ${ }^{16}$ Zira mukayese çoğunlukla değer yargılarının hâkim olduğu ideolojik ve söylemsel bir alan olmaktan kendini kurtaramamıştır.

1940lı yıllar ve öncesi, dinleri mukayese adı altında başlıca üç yaklaşıma şahit olmuştur: Illk yaklaşım dinler arası mukayese yapmak suretiyle Yahudi-Hıristiyan geleneğinin üstünlüğünü ispatlamaya çalışmıştır. İkinci yaklaşım, Yahudi-Hıristiyan dinî ögelerinin —örneğin bakire doğum, kurban vs. - pek çok farklı mitolojide tezahürlerinin olduğunu ispatlamak

14 Wach burada Hıristiyan vahiy teolojisinin mevzularından biri olan "özel" ve "genel" vahiy anlayışına değinmektedir.

15 Wach dinler teolojisini özellikle "General Revelation and the Religions of the World," "The Problem of Truth in Religion" ve "Radhakrishnan and the Comparative Study of Religion" adlı yazılarında ortaya koyar. Bu yazılardan ilk ikisi sonradan derlenen Understanding and Believing (1975), sonuncusu ise, Schilpp, P. A. (Ed.) (1992), The Philosophy of Sarvepalli Radhakrishnan'da bulunabilir.

16 Dinler tarihi/din bilimleri alanında mukayeseli çalışmalar için bk. Patton, K. C. ve Ray, B. C. (Ed.) (2000), A Magic Still Dwells. 
suretiyle bu geleneklerin manevi özünün ayağını kaydırmaya yönelmiştir. Bu yaklaşımın Carl Gustav Jung, Mircea Eliade ve Joseph Campbell ile devam eden üçüncü ve zıt ayağı ise dinlerdeki evrensel örgüler ya da ortak paydalar üzerinde durmak suretiyle onlardaki aşkın birliğe vurgu yapmaktadır. Örneğin, dünyanın dört bir yanındaki farklı dinî geleneklerde mevcut olan kurban ritüeli dinlerin aşkın birliğine işaret edecek şekilde yorumlanabilir. Fakat bu paralellik aynı zamanda Hıristiyan inancın özgün ve biricik olmadığı düşüncesine de hizmet edebilmektedir.

Mukayeseli din çalışmaları genel olarak pek çok yönden eleştiri alımış, Wach da yazılarında bu eleştirilerden nasibini alacak kadar fazla mukayese, genelleme, soyutlama ve sınıflandırma yapmıştır. Wach'ın mukayeseleri onun dinleri derecelendiren teolog yönünü ve değer yargılarını en bariz şekilde ortaya koyan unsurlardandır. Wach'a yöneltilebilecek eleştirileri şu şekilde sıralayabiliriz: Birincisi, Wach söz konusu ettiği her bir dinî gelenek hakkında birincil kaynakları kullanacak kadar yetkin değildir. ${ }^{17}$ Örneğin, İslam Peygamberi'nin tipolojisini yaratmada zamanının oryantalist anlayışını bire bir yansıtmış, İslam geleneğinin kendi sesini duyup aktarmaktan oldukça uzak kalmıştır. ${ }^{18}$ Bu durumda Wach, "diğer" dinî geleneklere ait şahıs ve fenomenlere Avrupa ve Hıristiyan teolojisi merkezli kavram ve kategorilerle yaklaşmaktan kendini kurtaramamıştır. Aslında Wach'ın yaptığı kendi Hıristiyan kökenli teolojik kavramlarını beynelmilel ölçekte muhtelif geleneklere giydirme işlemiydi. Örneğin, İslam dini ile ilgili muhtelif ögeleri Hristiyanlık ile mukayeseli bir şekilde değerlendiren Wach, İslamiyet'in şekillenişinde Hıristiyan geleneğinden büyük ölçüde etkilendiği görüşüne sahiptir. ${ }^{19}$ Zira bu anlayış İslamiyet'in ilk yıllarından Wach dönemi oryantalizmine kadar Hıristiyan dünyanın İslamiyet'e başlıca yaklaşımıydı. Aynı şekilde Wach'ın "karizma" anlayışı Kitab-ı Mukaddes kaynaklı olduğu gibi İslam Peygamberi onun anladığı şekilde bir din kurucusu değildir. Bu durum ise Wach'ın sadece soyut, bir şeyin üzerine giydirilmiş tipolojiler ve mukayeselerle değil aynı zamanda hegemonyacı bir teoloji ile hareket ettiğini göstermektedir.

Wach'ın, Mircea Eliade gibi, eleştirilebileceği diğer bir nokta ise mukayese ve sözde beynelmilel ölçekli tipolojilerinin dinî fenomenleri ve şahısları tarihî ve sosyal bütünlükleri içerisinde ele almamasıdır. Sonuç olarak bunlar test edilecek fenomenler olmaktan ziyade

17 Wach'ın eserlerinde başlıca iki nokta göze çarpmaktadır: Bunlardan ilki metodoloji ile çok fazla uğraşıp münferit olarak dinler ve onların ilk elden kaynakları üzerine yoğunlaşmamış olması, diğeri ise Wach'ın kendi sesini duymanın neredeyse imkansız oluşudur. Wach'ın yazıları muhtelif yazarların konu hakkındaki görüş ve bilgilerini sıraladığı bir alıntılar kumbarası gibidir. Dahası, Wach pek çok eserinde aynı noktaları yinelemekten öteye gitmez.

18 Örn. bk. Wach 1951: 78. Ayrıca bk. Avcı 2014.

19 Wach'ın Hıristiyanlık dışındaki gelenekler üzerinde derinlemesine yoğunlaştığı yazısı birkaçı geçmez. Bunlardan ilki Budizm'in bir kolu olan Mahayana üzerine yoğunlaştığı "The Study of Mahāyāna Buddhism” ile İslam tasavvuf geleneğini derinlemesine incelemeye çalıştığı "Spiritual Teachings in Islam with Special Reference to al-Hujwiri"dir. Sözünü ettiğim birinci çalışmada Wach, Mahayana Budizm'in tarihi, doktrinleri, yapısı vs. hakkında detaylı bilgi verdikten sonra yazısının son kısmında Hıristiyanlık ile karşılaştırmasını yapar. Bu karşılaştırmadaki amaç, bir Hıristiyan teoloğunun Mahayana Budizm hakkındaki bu bilgileri nasıl değerlendireceğini göstermektir. Fakat Mahayana Budizm ile Hıristiyanlığın sadece benzer değil farklı yönlerine de değinen birkaç sayfalık bu karşılaştırma, yüzeysel bir bilgilendirme olmaktan öteye gitmez. Bununla beraber Wach'ın Hıristiyanlık dışı bir dinî gelenek hakkında yaptığı bilgilendirmeyi Hıristiyan teoloğunun kullanımına sunması ve mukayeseyi bu amaçla kullanması gözlerden kaçmaz. Sözü edilen her iki yazı da Types of Religious Experience (1951)'da bulunabilir. 
büyük ölçekli hakikatler olarak sunulmuştur. Wach'ın mukayeselerinde dikkat çeken diğer önemli ayrıntı ise onun Hıristiyanlık dışı dinlerde de hakikat payı olduğuna inanan ve onlarla diyalog içerisinde olunması gerektiğini savunan bir dinler teoloğu olmasıdır. Tüm bunların yanı sıra Wach dinî tecrübenin farklı ifadeleri altında yatan aşkın bir maneviyatı savunur. $O$ aslında farklı dinlerin ışığında kendi Hıristiyan maneviyatının derinlerine inmeye çalışan bir imanlıdır.

Wach, dinler tarihi ve normatif teoloji arasındaki ilişkiyi ise şu şekilde ortaya koymaktadır: Dinler tarihi muhtelif dinî fenomenlerle ilgili bilgiler toplar ve onları yorumlar. Fakat ne mukayese ne de tipolojiler oluşturmak kendi başına yeterli değildir. Zira "objektif araştırma, mukayese ve tipoloji değerlendirmeye ulaşmak için zorunlu bir hazırlıktır" (Wach, 1951, s. 29). Wach, dinler tarihinin faydacı —ya da köprü vazifesi gören— bir disiplin olduğunun farkındadır. Zira o, Hıristiyanlık dışı dinler hakkında sağlanan bilgilerin filozof, teolog ya da sıradan bir araştırmacıya "hakikat" sorgulamasında yeni cevaplar sağlayacağı düşüncesindedir (Wach, 1951, s. 81). Sonuç olarak Wach’a göre dinler tarihçisinin toparladığı bilgiler teolog tarafından "normatif bir şekilde değerlendirilmediğinde bizim için bir anlam taşımayacaktır" (Wach, 1951, s. 28). Wach, aşağıdaki satırlarda da görüleceği üzere, dinler tarihinde "objektiflik" ile "değer yargılarının" bir arada bulunabileceğini iddia etmek suretiyle dinler tarihinin teolojiye nasıl evrilmesi gerektiğini itiraf etmektedir:

Yüzyılın dönemecinde "mukayeseli din" okulu tamamen "objektif" bir yaklaşım için değer yargılarını tasfiye etmeyi savunma yanlışına düşmüştür. Sonuç ise, sonsuz "hakikat" arayışına katkısı olmayan yetersiz bir rölativizm olmuştur. Aslında "hakikat" arayışı tüm bilme iştiyakımızın başlıca sebebidir.

Artık öğrendik ki, dinî tecrübenin tüm ifadelerinin yorumlanmasının iki amacı var: Birincisi, verilerin ortaya konulmasıdır ki, bu işlem tamamen objektiflik anlayışına bağlıdır. İkincisi, 'Tua res agitur,' parolasının öncülüğünde bu verilere karşı bizim takındığımız tavrın biçimlendirilmesi ve tanımlanmasıdır. Bu ise verilere değer biçilmesi anlamına gelmektedir (Wach, 1951, s. 7).

Burada teolojiden kasıt genel anlamda dinin ve dinî fenomenlerin metafizik hakikatini kabul etmektir. Bunu dinî düşünce ya da dindar yaklaşım olarak da adlandırabiliriz. Bu durumda Wach, başlarda ortaya koymaya çalıştığı dinler tarihinin "objektiflik," "tarafsızlık" ve "değer yargılarından uzak kalma" yönergesini üç yönden ihlal etmiştir. Zira Wach her ne kadar teolojiden uzak objektif bir dinler tarihçisi olmaya çalışsa da, Wiebe'nin deyişiyle, dinî fenomenleri "ontolojik hakikat"ler olarak görmektedir ve bu da bir çeşit teolojidir (Wiebe, 1999, s. 148). İkincisi, o bir Hıristiyan imanlısıdır ve diğer dinleri hakikatten pay alan fenomenler olarak değerlendirmektedir. Dahası kendi Hıristiyan maneviyatının bu dinlerdeki evrensel gerçekliklerle derinleşeceğine inanmaktadır. Üçüncüsü, Wach Yahudi-Hıristiyan kaynaklı bir dinî fenomenler tipolojisi yaratmıştır ki bu hegemonyacı ve dayatmacı bir sınıflandırmadır.

İnsanlık tarihini anlamanın en önemli yolunun din tarihinden geçtiği düsturundan yola çıkan Wach, dinler tarihi disiplinini insanı ve onun sahip olduğu dinî tecrübeyi anlama çabasının en mümbit alanı olarak gördü. Aslında, Wach'ın Religionswissenschaft ya da dinler tarihi disiplininden anladığı başlıca iki şeydi: Birincisi, Hıristiyanlık dışı dinler ve inanç gelenekleri, yani Budizm, İslam, Hinduizm vs. hakkında —-neredeyse tamamen ikinci ya da üçüncü el kaynaklardan — bilgi toplamak, bunları sınıflandırmak, tipolojiler oluşturup 
"klasik" olan fenomenleri sıralamak suretiyle dinî tecrübeyi anlamak; ${ }_{i}^{20}$ ikincisi, bu sıraladığımız faaliyetlerin bir yönerge çerçevesinde yapılmasını sağlamak ve bu yönergeyi ortaya koymak. Başka bir deyişle, Wach henüz oluşmaya başlayan bu alanın hem oyuncusu hem de teknik adamıydı. Wach'ın Religionswissenschft projesiyle —özellikle ilk dönemlerindeyapmaya çalıştığı, Hıristiyanlık dışı dinleri rasyonel-ampirik bir ölçütte tasvir eden, anlamlandıran, sınıflandıran, sonuç olarak da evrensel bir sistem olarak ortaya koyan yarı seküler bir "bilim" hâlinde sunmak olsa da, son zamanlarında onu elinde biriken "sistemli" dinler ansiklopedisine Hıristiyan kütüphanesinin hangi rafında yer açacağını düşünürken buluruz. Bu durum ise onun dinler tarihinin düsturları olarak ortaya koyduğu yönergeye ne ölçüde sadık kaldığını gözler önüne sermektedir.

Wach ilk döneminde dinler tarihini teolojiden ayırmayı söz konusu etmiş olsa da düşünce seyrine bakılacak olursa onu teolojinin, ya da kendi Hıristiyan maneviyatının, bir yardımcısı yapmaktan öteye gitmemiştir. Zira onun baştan itibaren amacı olan dinî tecrübeyi anlamak değer yargılarından uzak yüzeysel bir tasvirden fazlasını gerektirmektedir. Bu tarz bir anlama, Wach'da görüldüğü şekliyle, dinin hakikatini kabul etmek suretiyle kendini teolojide bulur. Timothy Fitzgerald, haklı olarak, dinler tarihi (bilimi) ya da din fenomenolojisinin "liberal ökümenik teolojinin gizlenmiş bir şekli" olduğunu iddia eder (Fitzgerald, 2000, s. 6). Bu durumda görülür ki, Wach'ın diğer bilimlerden bağımsız, objektif ve bilimsel bir disiplin hâline getirmeye çalıştığı dinler tarihi henüz kendi döneminde ve kendisi tarafından sekteye uğratılmıştır. Zira Religionswissenschaft köklerinden çıktığı teolojik yaklaşımdan kendini ayıramamıştır. Bu durum Wach'ın bahsi geçen yaklaşımı ile sınılı kalmamış, Mircea Eliade'nın "kutsal"ın peşindeki yeni hümanizm yaratma iddiası ile devam etmiştir. Bu durumda Wach her ne kadar din sosyolojisi ile ilgilendiğini iddia etse de din sosyolojisi adı altında yaptığı bir din fenomenolojisi, din fenomenolojisi adı altında yaptığı ise bir çeşit teolojidir. Üstelik bilimsel metodolojiyi önceleyen bir dinler tarihçisi olma iddiasında olan Wach, ne tam bir dinler tarihçisi ne de tam bir teolog olabilmiştir.

Sonuç olarak, Wach'ın entelektüel yaklaşımı çerçevesinde gördüğümüz otonom ve bilimsel bir disiplin olma iddiasındaki dinler tarihi aslında ne felsefe, ne teoloji, ne de temel bilimler kadar oturmuş bir statüye sahip olamamıştır. Aydınlanma'nın bir ürünü olarak değerlendirebileceğimiz yarı seküler bu alanın son yıllarda teolojiye yakın olduğunu, hatta bu alana mezcedilmesi gerektiğini savunanlar olduğu gibi ilahiyat disipliniyle bir alakası olmadığını, beşeri bilimler fakültelerine bağlanması gerektiğini savunanlar olmuştur. Bu durumda günümüzde filolojiyi de kapsayan alan çalışmaları dinler tarihi disiplinin yerini hızla almaktadır. ${ }^{21}$ önemli bir çalışmadır (Wasserstrom, 2010, s. 47).

21 Bu alanda devam eden tartışmalara güncel bir örnek olarak bk. Bird, D. L. ve Smith, S. G. (Ed.) (2009), Theology and Religious Studies in Higher Education. 


\title{
A Portrait of the Historian of Religions: Joachim Wach and His Faith Seeking Understanding
}

\author{
Betül AvcI*
}

\section{Objective}

Joachim Wach (1898-1955), considered one of the founding fathers of the contemporary history of religions, has a multilayered personality: In order, he is a historian of religions who tries to demarcate the field's boundaries and determine its methods, a phenomenologist of religion as he attempts to systematize the relationship between religion and society via typologies, and a faithful Christian who believes in the superior revealing of God in the person of Jesus Christ as well as a theologian who reflects upon how to approach non-Christian traditions. Within the scope of this paper, I will initially introduce Wach's three-layered intellectual approach and talk about his position in the history of religions. I will then discuss his task as a historian of religions, a sociologist and phenomenologist of religion, and a theologian. Finally, based upon Wach's approach, I will elaborate upon the relationship between the history of religions and the phenomenology of religion and question whether the former could liberate itself from theology.

\section{Jaochim Wach and Development of the History of Religions as a New Discipline}

In contrast to the approach of the Religionsgeschichtliche Schule (the History of Religion School), Wach tried to emancipate the history of religions from theology ${ }^{1}$ and to determine its methods, based on his assertion that it had a "scientific" character. However, as his interpreter Joseph M. Kitagawa notes, although this discipline is "religio-scientific" and "autonomous," "it does not claim to be a self-sufficient discipline" (Kitagawa, 1987, p. 17). In this respect, the history of religions should collaborate with normative (e.g. theology and philosophy) and descriptive (e.g. sociology and anthropology) disciplines (Kitagawa, 1987, pp. 17-18).

* Assist.Prof. Dr.,Yalova University, The Department of Religious Studies.

Correspondence: betulavci27@gmail.com. Address: Rüstempaşa Mh. Şehit Ömer Faydalı Caddesi No:146 Kat:3 Posta Kodu 77100 Merkez/Yalova.

1 Religionsgeschichtliche Schule is often translated as "history of religions." However, as William Baird notes, such a translation is not accurate because "s" does not denote plurality, but rather the genitive singular (Baird, 2003, p. 222). For further information on Religionsgeschichtliche Schule, see Chapman, M. D. (2010), History of Religion School. 
In addition to Wilhelm Dilthey and Gerardus van der Leeuw, Eric Sharpe cites Friedrich Heiler, Ernst Troeltsch, Adolf von Harnack, Nathan Söderblom, Rudolf Otto, and Max Weber as being among those who influenced Wach (Sharpe, 1975, p. 238). ${ }^{2}$ Rainer Flasche distinguishes two phases in Wach's intellectual history: Wach developed the historical and philosophical bases of the Religionswissenschaft and, at a later date, turned into a theologian of religions (Flasche, 1978, p. 73). ${ }^{3}$ Kitagawa distinguishes three phases in Wach's intellectual career: trying to determine the history of religions' methodology as he searches for an understanding within his hermeneutical approach, focusing on the sociology of religion, and reviewing the relationship between the history of religions and the social sciences, philosophy, and theology (Kitagawa, 1988, pp. ix-xxxiv).

\section{Wach as a Historian of Religions}

In the first phase of his intellectual career, Wach authored Religionswissenschaft:Prolegomena zu ihrer wissenschaftstheoretischen Grundlegung (1924) and Das Verstehen (1926-1933). In the former work he seeks to set the history of religions apart from the normative disciplines and to relate the field's goal and methods. ${ }^{4}$ According to him, this descriptive and interpretative discipline distinguishes itself from normative, ideological, and faith-based approaches by seeking to employ empirical data and to approach religious phenomena both historically and systematically. In other words, this field concentrates on discovering the principle that erects a structure around the systematized empirical data and reaching the underlying meaning. Although he argues that systematization is not summarizing, grouping, or classifying, his typologies could not go any further than these (Wach, 1988a, pp. 121-122). One of the methods employed by Religionswissenschaft is phenomenology which tries to systematize religious phenomena, namely, classification (Wach, 1944, p. 1, ff. 3). ${ }^{5}$ Thus, he builds his sociology of religion upon these classifications, which he calls "typologies." Consequently, as James Cox also notes, "Wach's sociology of religion was phenomenological through and through" (Cox, 2006, p. 173).

\section{Sociology of Religion, Phenomenology of Religion and Wach}

During the second phase of his intellectual life, Wach explored the social dimension of religious experience by means of his typologies, or, in his own words, the systematical dimension of religious phenomena. This is when he acted as a constructive phenomenologist following Gerardus van der Leeuw, and as a sociologist of religion following Max Weber. However, although inspired by Weber, Wach does not provide us with a full discourse based upon his work is employed in Turkish-speaking academia as a main source of the history of religions. For an example of Wach written in Turkish see Alıcı, M. (2005), Kutsal'a Giden Yol: Dinler Tarihi'nde Bir Metodolojik Yaklaşım veya Bir Bilim Olarak Din Fenomenolojisi.

Also see Kitagawa for further information on details of Wach's life (Kitagawa, 1958, pp. xiii-xlviii).

Also see Charles M. Wood's Theory and Understanding: A Critique of the Hermeneutics of Joachim Wach (1975).

For further information on the phenomenology of religion, see Allen, D. (2005). 
collected empirical data and hence is not as assertive as Weber. This is because his sociology of religion goes no further than a phenomenology of religion based upon comparisons and typologies. This is the context within which he wrote Einführung in die Religionssoziologie (1931), Typen religiöser Anthropologie (1932), and Sociology of Religion (1944).

Wach held that historians of religions should use typology and comparison to explore religious traditions and systematize their data in order to understand them. He offers various categories of religious phenomena which he calls "types" in his Sociology of Religion and in The Comparative Study of Religion, and then categorizes religious phenomena based upon their similarities. However, as Gregory Alles also notes, "in Wach's case, typology appears as a technique of management, not of political administration but of conceptual management in an increasingly complex religious environment" (Alles, 2010, p. 58). Wach's typologies attract our attention when-or in the context which-he deals with sociology of religion. However, since he maintained that historians of religions should not reach evaluative judgments, he was well aware that his task could produce nothing more than typologies (Wach, 1951, pp. 228-229). For him, this is the point where typology is related to both philosophy and theology and when philosophy and theology should set off (Wach, 1988b, p. 133).

\section{Wach and His Theology}

Wach employs comparison not only when constructing his typologies, but also when comparing his own Christian experience with other religious traditions. During this period he is the faithful Christian who learns and teaches "other" religions and seeks to understand his own religious experience for, as he notes, "certain parts of religious experience can help deepen our own religious experience." He searches for a deeper religious understanding and tries to find a common reality behind various religious expressions. For him, comparison "is an interesting means of discovering the character of religion" (Wach, Lecture Notes, p. 68). Wach expands upon the issue of comparison in The Comparative Study of Religions and notes that: "A comparative study of religions such as the new era made possible enables us to have a fuller vision of what religious experience can mean, what forms its expression may take, and what it might do for man" (Wach, 1958, p. 9).

The third phase or approach in his intellectual life occurred in Chicago during 1945-1955. This is when he acts as a Christian theologian who explores the relationship between the history of religions and theology in addition to the relationship between Christianity and other religions. He presented the results of his research in Types of Religious Experience: Christian and non-Christian (1951) and, posthumously The Comparative Study of Religions (1958). It is also fair to include Understanding and Believing (1968), a posthumously published collection of his essays and addresses in this time period.

According to Wach, theology may have as one of its secondary goals an interest in "other religions." At this point, history of religions that looks for an "understanding of other religions" takes the lead (Wach, 1975, p. 130). In this context, he informs us about the comparative study of religions. As he argues, discovering similarities and relationships among religions does not have a negative effect on a person's own religious conviction. On the contrary, while "it could become a support and an aid in the battle against the godless 
and estranged powers," it should "lead to the examination and preservation of one's own religious faith" (Wach, 1975, p. 128).

Meanwhile, he also appears as a faithful Christian who believes in God's superior revelation in Christianity. His comparisons once again signal his prioritizing Christianity over other religious traditions, based on his opinions that not all religions traditions are on the same level and that Christianity enjoys the most advanced status. For example, as Wach notes, "the Christian God cannot be the unconcerned blissful One of the Vedanta nor the alien god of the gnostic, nor the exclusively stern judge of the Talmud or the Quran..." (Wach, 1975, p. 90). Although he believes that other religions contain experiences of the real, this should not mean that they are subject to a "special" revelation, as is the case with Christianity. On the contrary, "lesser revelations" prove the uniqueness of the Christian revelation (Wach, 1975, pp. 75-76). ${ }^{6}$ Moreover, Wach is a missionary who searches for ways to spread the Christian message throughout the world, as he states in his "Redeemer of Man" and "Belief and Witness."7

\section{Conclusion: The Comparisons, Typologies and Theology of Wach}

Wach viewed the history of religions as the most productive sphere in which to understand universal human religious experience. In fact, for him, this field denotes the following: (1) Collecting data related to the religious phenomena of various non-Christian religious traditions, comparing and classifying them, and then creating typologies in order to reach an understanding of religious experience ${ }^{8}$ and (2) providing a methodology to achieve this task. Thus, although he attempted to create a universal, quasi-secular scientific system that prioritizes objectivity and the suspension of value judgments, he ultimately failed because his comparisons and typologies show that he was a theologian who evaluated religious phenomena. ${ }^{9}$

The following points, in order, should be considered a critique of Wach:

1) Wach is not thoroughly competent in each of the religious traditions that he discusses. For instance, he reflects the orientalist approach of his time by creating a typology of Prophet Muhammad without referring to the traditional Islamic approach. ${ }^{10}$ In this respect, he approaches other religious traditions and phenomena based upon his own European and Christian tradition and thus creates hegemonic and imposed categories.

2) Similar to Mircea Eliade, he removes religious phenomena and personages from their social and historical contexts and, consequently, creates "universal" abstractions devoid of particularities. Moreover, although Wach claims to be an objective historian of religions, as

Wach's theology of religions appears particularly in his "General Revelation and the Religions of the World" (1954). As Kitagawa notes, this article developed out of his 1953 speech he gave at the National Association of Biblical Instructors in Evanston, Illinois (Kitagawa, 1975, p. xv).

7 Both works are in Wach's Understanding and Believing (1975).

8 Wasserstrom views Wach as a Kierkegaardian "existential theologian" (Wasserstrom, 2010, p. 47).

9 For a sample of works on comparison in religious studies, see Patton, K. C. \& Ray, B. C. (Eds.) (2000), A Magic Still Dwells.

10 See Avcı, B. (2014), Joachim Wach'ın Religionswissenschaft Çerçevesinde İslam Dinine Yaklaşımı. 
liberated from theology, in Wiebe's wording he views religious phenomenon as an "ontological reality" and therefore constructs a type of theology (Wiebe, 1999, p. 148).

3) Wach's comparisons and typologies reveal him to be a theologian who evaluates religious phenomena. Likewise, he presents us with a theology of religions because he believes that truth exists in non-Christian religions. Moreover, although not a relativist, he does believe in a transcendent spirituality that lies behind various religious experiences. In fact, he is a faithful Christian who tries to get deeper into his own spirituality in light of other religious expressions.

Although Wach sought to distinguish the history of religions from theology, he only managed to turn it into an aid for theology or for his own Christian spirituality, ${ }^{11}$ because his goal of understanding requires more than a superficial description devoid of value judgments. Such a faith seeking understanding that acknowledges the truth of religion finds its scope within theology. Thus, as Timothy Fitzgerald fairly argues, religious studies or the phenomenology of religion "is a disguised form of liberal ecumenical theology" (Fitzgerald, 2000 , p. 6). In this respect, Wach's attempt to establish the history of religions as an autonomous, objective, and scientific discipline failed even in his own eyes as he involved himself in the phenomenology of religion under the name of the "sociology of religion." In addition, he acts as a quasi-theologian when he is involved in the phenomenology of religion. Moreover, although Wach seems to be a historian of religions who prioritizes methodology, he did not fit completely into either the field of the history of religions or theology.

\section{Kaynakça/ References}

Allen, D. (2005). Phenomenology of Religion. J. Hinnells (Ed.), The Routledge Companion to the Study of Religion içinde (s. 182-207). London and New York: Routledge.

Alles, G. (2010). After the Naming Explosion: Joachim Wach's Unfinished Project. C. K. Wedemeyer ve W. Doniger (Ed.), Hermeneutics, Politics and the History of Religions: The Contested Legacies of Joachim Wach \& Mircea Eliade içinde (s. 51-79). New York: Oxford University Press.

Alıcı, M. (2005). Kutsal'a Giden Yol: Dinler Tarihi'nde Bir Metodolojik Yaklaşım veya Bir Bilim Olarak Din Fenomenolojisi. Din Bilimleri Akademik Araştırma Dergisi, 5 (3), 73-120.

Avcı, B. (2014). Joachim Wach'ın Religionswissenschaft Çerçevesinde İslam Dinine Yaklaşımı. İstanbul Üniversitesi Ilahiyat Fakültesi Dergisi, 30, 195-216.

Baird, W. (2003). History of New Testament Research Volume 2: From Jonathan Edwards to Rudolf Bultmann. Minneapolis: Fortress Press.

Bird, D. L. ve Smith, S. G. (Ed.). (2009). Theology and Religious Studies in Higher Education: Global Perspectives. London \& New York: Continuum International Publishing Group.

Chapman, M. D. (2010). History of Religion School. D. Fergusson (Ed.), The Blackwell Companion to the Nineteenth Century Theology içinde (s. 434-454). Chichester, U.K., Malden, Mass.: Wiley-Blackwell.

Cox, J. L. (2006). A Guide to the Phenomenology of Religion: Key Figures, Formative Influences and Subsequent Debates. New York: The Continuum International Publishing Group.

Fitzgerald, T. (2000). The Ideology of Religious Studies. New York, Oxford: Oxford University Press.

Flasche, R. (1978). Die Religionswissenschaft Joachim Wachs. Berlin, New York: W. de Gruyter.

11 For a collection of recent discussions on the distinction between religious studies and theology, see Bird, D. L. \& Smith, S. G. (Eds.) (2009), Theology and Religious Studies in Higher Education. 
Kitagawa, J. M. (1958). Introduction: The Life and Thought of Joachim Wach. J. Wach, The Comparative Study of Religions içinde (s. xiii-xlviii). New York: Columbia University Press.

Kitagawa, J. M. (1975). Introduction. J. Wach, Understanding and Believing: Essays by Joachim Wach içinde (s. vii-xviii). Westport: Greenwood Press.

Kitagawa, J. M. (1987). The History of Religions: Understanding Human Experience. Atlanta, Georgia: Scholars Press.

Kitagawa, J. M. (1988). Introduction: Verstehen and Erlösung. J. Wach, Introduction to the History of Religions içinde (s. ix-xxxiv). New York: Macmillan.

Patton, K. C. ve Ray, B. C. (Ed.). (2000). A Magic Still Dwells: Comparative Religion in the Postmodern Age. Berkeley, California: University of California Press.

Sharpe, E. J. (1975). The Comparative Religion: A History. London: Duckworth and Co.

Wach, J. Lecture Notes Related to Comparative Study of Religions, 6. Kutu 10. Dosya, Special Collections Research Center at the University of Chicago Library.

Wach, J. (1944). Sociology of Religion. Chicago: University of Chicago Press.

Wach, J. (1951). Types of Religious Experience: Christian and Non-Christian. Chicago: The University of Chicago Press.

Wach, J. (1958). The Comparative Study of Religions. New York: Columbia University Press.

Wach, J. (1975). Understanding and Believing: Essays by Joachim Wach. Westport: Greenwood Press.

Wach, J. (1988a). Introduction to the History of Religions. New York: Macmillan Publishing Company.

Wach, J. (1988b). Essays in the History of Religions. New York: Macmillan Publishing Company.

Wach, J. (1992). Radhakrishnan and the Comparative Study of Religion. P. A. Schilpp (Ed.), The Philosophy of Sarvepalli Radhakrishnan içinde (s. 443-458). Delhi: Motilal Banarsidass Publishers.

Wasserstrom, S. M. (2010). The Master-Interpreter: Notes on the German Career of Joachim Wach (1922-1935). C. K. Wedemeyer ve W. Doniger (Ed.), Hermeneutics, Politics and the History of Religions: The Contested Legacies of Joachim Wach \& Mircea Eliade içinde (s. 21-50). New York: Oxford University Press.

Wiebe, D. (1999). The Politics of Religious Studies. New York: Palgrave.

Wood, C. M. (1975). Theory and Understanding: A Critique of the Hermeneutics of Joachim Wach. Missoula, Mont.: Scholar's Press. 
